\title{
Análise de comportamentos do odontólogo no contexto de atendimento infantil ${ }^{1}$
}

\author{
Gustavo S. Rolim \\ Antônio Bento Alves de Moraes \\ Universidade Estadual de Campinas \\ José César \\ Universidade Metodista de Piracicaba \\ Áderson Luiz Costa Junior \\ Universidade de Brasília
}

\begin{abstract}
Resumo
A pesquisa comportamental em odontologia tem permitido reconhecer padrões de interação do cirurgiãodentista com seu cliente, assim como, propor formas de intervenção sistemática que contribuam para a facilitação do atendimento clínico. Este trabalho teve como objetivo analisar funcionalmente os comportamentos do cirurgião-dentista em uma sequiência de sessões de atendimento odontológico de uma criança. Todas as sessões foram registradas em vídeo e os episódios de interação comportamental profissional-cliente descritos na íntegra. Os comportamentos foram classificados em categorias conforme sua funcionalidade. Os resultados mostraram que o tratamento odontológico envolve um controle bidirecional entre seus participantes ativos. O dentista utiliza-se da instrução e distração, enquanto estratégias de manejo de comportamentos colaborativos, assim como, de contenção física e punição verbal para o controle de eventos não-colaborativos. Os resultados permitiram supor que o que leva o dentista a atuar de modo particular, parece ser o padrão comportamental da criança, assim como sua história de aprendizagem ao contexto de tratamento.
\end{abstract}

Palavras-chave: análise funcional do comportamento; relação cirurgião-dentista paciente; psicologia e odontologia

\begin{abstract}
The dentist's behavior analysis in the context of children treatment. Behavioral research in Dentistry has created possibilities of knowing different patterns of interaction between dentist and patient as well as procedures to improve dental care. The aim of the present study was to analyze the behavior of two dentists and a five-year old child, during clinical dental treatment. Dental treatment events were recorded and then described based on a functional analysis framework. Behaviors were classified into categories and analyzed in terms of actionsantecedent and consequential events. Results showed that dental treatment involves a bi-directional control of patient and dentists' behavior. Instruction and distraction were the main management procedures of cooperative behavior. Physical restraint and verbal punishment were often used to control uncooperative behaviors. The results showed that what leads a dentist to have such behavior might be closely related to how the patient behaves as well as how much expertise the dentist has on dental treatment for children.
\end{abstract}

Keywords: functional behavior analysis; dentistry-patient relationship; psychology and dentistry

A história da análise funcional do comportamento, como hoje é conhecida, começou com a proposição original de Skinner (1945) sobre a contingência tríplice e esta se tornou um dos principais instrumentos do analista do comportamento para a análise das interações entre repertórios comportamentais e variáveis que os determinam. Para descrever as relações que se estabelecem entre indivíduos e ambientes, isto é, para a realização de análises funcionais, a tríplice contingência deve especificar três termos: (a) a ocasião na qual ocorreu a resposta; (b) a própria res- posta; e (c) as conseqüências reforçadoras (Skinner, 1953). Ao analisar um comportamento, interessam ao pesquisador três perguntas: o que acontece? Quais as circunstâncias? Com que conseqüências?

O comportamento humano é modelado pelo ambiente e as distinções entre comportamentos adequados e inadequados resultam de padrões de reforçamento a que estes foram expostos. Resultado de aprendizagem, o comportamento ocorre em função não só de eventos antecedentes (como a história de vida e os estímulos discriminativos), mas também, em 
função de eventos conseqüentes (como os estímulos reforçadores e aversivos). $\mathrm{O}$ uso de adjetivos como inadequado ou desajustado é efetuado em relação aos padrões de comportamento, e não à pessoa. Um comportamento "desviante" não pode ser visto como disfuncional, já que é uma resposta apropriada às contingências presentes no contexto em que ocorre.

As formas, desviantes ou não, com que uma pessoa lida com situações aversivas ou inéditas, podem ser caracterizadas como produto de situações de enfrentamento, isto é, os acontecimentos do cotidiano exigem respostas no sentido de um esforço para adaptação do indivíduo ao meio. $\mathrm{O}$ enfrentamento pode ser compreendido como sendo um conjunto de respostas às condições de vida, reais ou não (Cerqueira, 2000; Coutinho, Costa Jr., \& Kanitz, 2000).

Vanderberghe (2002) compreende que a análise funcional prioriza a interação e o controle do comportamento em termos bidirecionais. Estudar as variáveis que determinam o repertório de comportamentos de um indivíduo requer analisar as formas e os padrões comportamentais do indivíduo em cada configuração de ambiente a que este está exposto.

Matos (1997) enfatiza que o Behaviorismo Radical se propõe a uma interpretação de dados obtidos por investigações sistemáticas acerca da ocorrência de comportamentos. Essa interpretação enfatiza a descrição de relações entre comportamento e ambiente (contexto), ou seja, relações entre descrições de ações dos organismos e descrições das condições em que essas ações se dão. Portanto, busca explicar por meio de relações funcionais, seqüências regulares de eventos. Tal pressuposto exige que a obtenção das informações deva ocorrer ao longo do tempo, isto é, informações repetidas do mesmo evento e com os mesmos personagens.

\section{A análise funcional em situação de tratamento odontológico}

A análise funcional é realizada em diversos contextos de interação humana, por exemplo, na clínica psicológica, na escola e em serviços de saúde, incluindo situações de atendimento odontológico, objeto de estudo deste trabalho.

Segundo Moraes (1997), o tratamento odontológico ocorre por meio de um conjunto complexo de comportamentos de um indivíduo (o profissional) que acontecem diante de um outro (o paciente), que por sua vez apresenta respostas que podem ou não estar "ajustadas" às necessidades do tratamento. Tratar os dentes de um paciente é uma maneira de se comportar profissionalmente diante de indivíduos, que, além de problemas de saúde bucal, tendem a expressar, também, comportamentos indicadores de medo, ansiedade e tensão emocional (Moraes \& Pessotti, 1985).

Embora a situação do tratamento odontológico constitua uma condição para provável exposição a episódios de dor e desconforto ao paciente, pode, também, referir uma situação de reforçamento positivo, entretenimento e aprendizagem de comportamentos de saúde, mediante a adoção de estratégias comportamentais, pelo dentista, apontadas pela literatura como amenizadores da percepção de ansiedade e de perda de controle situacional (Liddel \& Locker, 2000).
Mecanismos de adaptação do paciente à situação de tratamento odontológico, conhecidos há algum tempo, incluem procedimentos contínuos e repetitivos de ensinar o paciente a como se comportar ao longo de rotinas odontológicas específicas, aumentando-se, gradativamente, a exigência por comportamentos colaborativos (Moraes \& Pessotti, 1985). Neste sentido, o manejo de comportamentos do paciente pelo cirurgião-dentista inclui, por exemplo, o imediato reforçamento positivo de respostas iniciais e minimamente colaborativas, tais como seguir instruções básicas de sentar-se à cadeira odontológica, abrir a boca e permitir o exame clínico. Tais procedimentos atuam, também, para otimizar a relação profissional-paciente, aumentando a adesão do paciente ao tratamento e reduzindo a probabilidade do uso de estratégias coercitivas para obtenção de colaboração.

Alguns estudos também apontam para a necessidade de se introduzir, na situação de atendimento odontológico, outros estímulos que mantenham o comportamento do paciente de enfrentar a situação. Tais estímulos devem de alguma maneira, competir com os estímulos do consultório que são percebidos como aversivos, reduzindo a probabilidade da ocorrência de comportamentos de fuga e esquiva à situação de tratamento (Allen, Loiben, Allen, \& Stanley, 1992; de Jongh, Muris, Horst, \& Duyx, 1995).

Embora obtenha ganhos, em termos de saúde bucal, quando se submete ao tratamento odontológico, o comportamento do paciente é controlado por regras e intervenções clínicas, muitas vezes coercitivas. Estudos apontam que a exposição às contingências do atendimento odontológico proporciona a aquisição de padrões de não-colaboração, especialmente em crianças (Possobon, 2000). Dor e desconforto são eventos estressantes que tendem a ocorrer antes que os pacientes percebam os benefícios à saúde proporcionados pelo tratamento, o que conduz ao aumento da sensação de medo do tratamento odontológico e que se apresenta sob a forma de não-colaboração ou "resistência". Todavia, o cirurgiãodentista nem sempre está atento à aversividade do tratamento odontológico e acaba utilizando estratégias de contenção física, com o intuito de preservar a integridade física do paciente e permitir a execução dos procedimentos técnicos que integram o tratamento.

Weinstein, Getz, Rateener e Domoto (1982) estudaram as diferenças entre crianças que apresentavam comportamentos indicadores de medo e crianças que não apresentavam tais comportamentos quando expostas a atendimento odontológico. Os resultados mostraram que o dentista responde aos comportamentos de medo do paciente com ordens, punições e persuasões, ao invés de utilizar instruções, distrações ou outras estratégias construtivas.

Stark, Allen, Hurst, Nash, Rigney e Stokes (1989) observaram que a distração constitui uma estratégia eficaz para a redução da ansiedade, conseqüentemente de comportamentos de fuga e esquiva que as crianças podem manifestar sob tratamento odontológico. Todavia, os autores advertem que o uso de distração, seguida de recompensa ou prêmios, não seria uma estratégia eficaz para o manejo de comportamentos não-colaborativos, uma vez 
que tendem a aumentar a freqüência de ocorrência de padrões de fuga e esquiva do tratamento.

Segundo Ten Berge, VeerKamp e Hoogstraten (1999), a intensidade de medo de tratamento odontológico em crianças diminui com o decorrer no tratamento. Dados do estudo apontaram que os escores de medo foram significativamente mais baixos durante a quarta sessão curativa, quando comparados à primeira sessão curativa. Os autores observaram que os dentistas utilizavam-se especialmente de estratégias de ordem para obter controle sobre as crianças identificadas como "altamente temerosas". Conforme relato dos autores, em alguns casos, quando a criança se recusava a colaborar, era praticamente impossível tratá-la sem algum tipo de "restrição física". O estudo permite sugerir que comportamentos coercitivos do dentista estavam controlados pelo nível de medo que a criança manifestava durante o tratamento.

Singh, Moraes e César (2002) discutem os efeitos da adoção de estratégias de restrição física sobre o repertório de comportamentos colaborativos de pacientes expostos a tratamento odontológico. Os autores discutem se a criança colaborou com o atendimento devido à submissão compulsória (contenção física), ou se colaborou por ainda estar controlada pela exposição a estímulos aversivos condicionados da situação.

O presente trabalho teve como objetivo analisar funcionalmente como as unidades comportamentais do paciente, combinadas com outros elementos do contexto odontológico, se relacionavam aos comportamentos do cirurgião-dentista, e de que modo esta interação contribuía, ou não, para a execução do tratamento.

\section{Método}

\section{Participante}

Tomou parte no estudo uma paciente do sexo feminino, com 4 anos e 5 meses de idade, com desenvolvimento típico, que recebeu tratamento odontológico habitual, ao longo de sete sessões de atendimento executadas por um cirurgião-dentista do Centro de Atendimento Odontológico para Pacientes Especiais (Cepae), da Faculdade de Odontologia de Piracicaba, da Universidade Estadual de Campinas (FOP/UNICAMP).

A criança apresentava boas condições de saúde geral, avaliada por meio de observação e entrevista com a mãe. A história de experiências da criança com tratamento odontológico incluía duas tentativas de exame clínico, sem sucesso, em um serviço público municipal de odontologia. Conforme relato da mãe, embora tenha se sentado à cadeira odontológica, a criança não permitiu o exame clínico de seus dentes e ainda apresentou alta freqüência de choro e protestos verbais, sendo dispensada pelo profissional. Um critério de inclusão da paciente na pesquisa foi o relato de uma história de não colaboração em situação de atendimento odontológico.

\section{Procedimento}

O tratamento odontológico foi realizado nas dependências do Laboratório de Psicologia Aplicada, unidade do Cepae/ FOP/UNICAMP, composta por uma sala de espera, um consultório odontológico padrão e uma sala de observação com visor unidirecional. As sessões de atendimento foram registradas em vídeo, utilizando-se uma câmera de VHS, instalada na sala de observação. As fitas receberam marcas sonoras eletrônicas a cada 15 segundos.

As fitas das sessões de atendimento foram, posteriormente, observadas e analisadas seqüencialmente por dois observadores independentes, registrando-se os eventos comportamentais na íntegra, verbais e motores, emitidos pelo cirurgião-dentista e pela paciente, a cada intervalo de 15 segundos.

Os comportamentos foram classificados em categorias funcionais, de modo a identificar temáticas comuns nas diferentes respostas emitidas pelo cirurgião-dentista. Deste modo, cada categoria de comportamento poderia aparecer isoladamente ou constituindo pares, conforme exemplo explicitado na Tabela 1: ajuda física e ajuda física/ordem.

Tabela 1

Apresentação dos comportamentos do cirurgião dentista em antecedentes, respostas do dentista, categoria e comportamentos conseqüentes

\begin{tabular}{|c|c|c|c|}
\hline Antecedentes & Respostas do CD & Categoria & Conseqüentes \\
\hline $\begin{array}{l}\text { Criança colabora } \\
\text { Mãe segura perna } \\
\text { direita da criança }\end{array}$ & $\begin{array}{l}\text { Coloca a criança sentada no } \\
\text { espaldar da } \mathrm{CO} \\
\text { Deita a criança na CO }\end{array}$ & Ajuda fisica & Criança choraminga \\
\hline $\begin{array}{l}\text { Criança encolhe } \\
\text { ombros } \\
\text { Gira tronco e pernas } \\
\text { para sair da CO }\end{array}$ & $\begin{array}{l}\text { Pega criança nas axilas } \\
\text { Coloca criança deitada na CO } \\
\text { Diz: - "Não, não pode descer, a } \\
\text { gente ainda não acabou de } \\
\text { conversar" }\end{array}$ & $\begin{array}{l}\text { Ajuda física } \\
\text { Ordem }\end{array}$ & Criança colabora \\
\hline
\end{tabular}


O registro de freqüência de cada comportamento da criança está relacionado a cada resposta emitida pelo cirurgiãodentista. Assim, respostas físicas e verbais que aconteceram concomitantemente formaram categorias específicas diferentes. A concordância média, entre observadores independentes, alcançada após as categorizações das sessões transcritas, foi de $99,06 \%$.

\section{Resultados}

A apresentação dos resultados está dividida em três etapas: (a) na primeira, descreve-se, qualitativamente, as rotinas clínicas realizadas em cada sessão e os comportamentos do cirurgião-dentista, em função do repertório de comportamentos da criança; (b) a seguir, analisa-se, quantitativamente, o repertório de comportamentos da criança e do cirurgião-dentista, apontando-se possíveis relações funcionais entre os eventos; (c) finalmente, os comportamentos do cirurgião-dentista são analisados em relação às seqüências de interação com a criança.

\section{Descrição das sessões de atendimento}

$\mathrm{Na}$ primeira sessão, estava prevista a execução de um exame clínico dos dentes, bem como os procedimentos de evidenciação de placa, treino de escovação, profilaxia e aplicação tópica de flúor. No início, o cirurgião-dentista utilizou a técnica de conte-mostre-faça (Addelston, 1959) para adaptar a criança ao ambiente odontológico. A criança sentou-se à cadeira odontológica e manteve atenção às informações do profissional. Durante o exame clínico e a evidenciação de placa bacteriana, a criança foi colaborativa. Todo comportamento colaborativo era reforçado socialmente pelo profissional (com verbalizações do tipo: "muito bem", "você fez tudo direito", "quando você se comporta assim, você fica mais bonita"). O cirurgião-dentista explicou os passos do procedimento de escovação e treinou sua execução com a participação ativa da criança. A profilaxia e aplicação tópica de flúor também foram executadas com colaboração da criança.

$\mathrm{Na}$ segunda sessão, o cirurgião-dentista manteve a técnica do conte-mostre-faça, iniciando a execução de cada rotina odontológica com instruções e demonstrações. A criança apresentou comportamentos colaborativos durante o exame clínico, mantendo padrão comportamental semelhante à primeira sessão. Entretanto, assim que foi aplicado o anestésico tópico, a criança, apresentou alta freqüência de choro e não permitiu o término da anestesia. O dentista adotou estratégias de persuasão, oferecendo prêmios condicionados à colaboração, sem sucesso. A sessão foi encerrada sem a conclusão da anestesia tópica. Observou-se que a ocorrência da não-colaboração da criança, contingente às rotinas de tratamento, impediu a emissão de comportamentos de elogio ou conversas de caráter distrativo por parte do cirurgião-dentista. Por outro lado, comportamentos não-colaborativos da criança aumentaram a probabilidade da utilização de estratégias de persuasão e punição verbal do profissional.

Na terceira sessão, a criança encaminhou-se para a cadeira odontológica sem que o dentista tivesse que solicitar, sendo imediatamente elogiada. Foram executadas as rotinas clínicas de exame clínico, anestesia tópica e início de anestesia injetável. A criança apresentou comportamento colaborativo durante todo o exame clínico e anestesia tópica, embora tenha reclamado no início da aplicação tópica do anestésico. Após esta rotina, o dentista instruiu a criança sobre a anestesia injetável, que seguiu prontamente as orientações. No início da aplicação do anestésico injetável, no entanto, a criança apresentou grande intensidade de choro, interrompendo a rotina com movimentos do corpo, levantando-se da cadeira e não mais permitindo a continuidade do atendimento. A sessão foi encerrada.

Na quarta sessão, o dentista pediu à criança que se sentasse à cadeira odontológica, elogiando-a pelo cumprimento da instrução. O dentista instruiu a criança sobre seu comportamento durante a rotina de anestesia tópica. A criança, no entanto, não permitiu a aplicação do anestésico, apresentando um padrão estável de comportamentos de fuga, com choro, tentativas de descer da cadeira e segurando a haste do refletor, impedindo que o dentista pudesse aproximar-se de sua boca. A criança foi dispensada e a sessão encerrada.

$\mathrm{Na}$ quinta sessão, a criança permaneceu colaborativa durante a rotina exame clínico, mas, novamente, não permitiu a aplicação do anestésico tópico, recusando-se a deitar na cadeira odontológica e segurando a haste do refletor. Frente a comportamentos de fuga e esquiva, o dentista utilizou-se de estratégias instrucionais para manter a criança sentada na cadeira odontológica e atenta às suas orientações. A criança apresentou comportamentos motores menos intensos que na sessão anterior, mas não permitiu a realização de qualquer rotina odontológica.

No início da sexta sessão, o dentista informou à criança que o atendimento seria realizado mesmo que não houvesse sua colaboração. A contenção física seria a estratégia utilizada para mantê-la na cadeira odontológica. O dentista explicou à criança que o tratamento seria realizado e se ela colaborasse, a sessão seria mais rápida e confortável, não havendo necessidade de contenção. A criança, colocada na cadeira odontológica, mas recusando-se a deitar, foi contida pela mãe e pela auxiliar, enquanto as rotinas clínicas eram executadas. A criança resistiu à contenção com intensos movimentos corporais e choro, embora durante a anestesia injetável, tenha apresentado choramingo, sem movimentos do corpo. Ao término da sessão, a criança parecia calma e atendia às instruções do dentista, respondendo, inclusive, às estratégias de distração adotadas pelo profissional.

Na sétima sessão, a criança apresentou amplo comportamento colaborativo, permitindo a realização de todas as rotinas clínicas. O dentista elogiou cada comportamento colaborativo, distraindo a criança com cantos e conversa, enquanto realizava o tratamento.

\section{Descrição quantitativa de comportamentos da criança e do dentista}

A descrição pormenorizada e categorização dos comportamentos do cirurgião-dentista permitiram sua classificação em quatro grupos funcionais: (a) categorias interativas; (b) 
categorias diretivas; (c) categorias distrativas; e (d) categorias punitivas. Os comportamentos da criança estão divididos em duas categorias: (a) comportamento colaborativos; e (b) comportamentos não-colaborativos.

A Tabela 2 apresenta a freqüência relativa dos comportamentos da criança, em função dos comportamentos do cirurgião-dentista, considerando os dados da quarta até a sétima sessão de atendimento. Para o cálculo da freqüência relativa de comportamentos da criança, o total das ocorrências de cada categoria foi dividido pelo tempo de duração de cada sessão. Assim, para cada categoria de comportamento do cirurgião-dentista há a correspondência, em freqüência relativa, dos comportamentos colaborativos e não-colaborativos da criança. A somatória das freqüências relativas das categorias de comportamento da criança representa a freqüência relativa de cada categoria do cirurgião-dentista. Na Tabela 2, estão apresentadas apenas as categorias que tiveram ocorrência igual ou superior a duas emissões por sessão.

Tabela 2

Freqüência relativa de colaboração $(C)$ e não colaboração $(N C)$ relacionada às categorias de comportamentos do cirurgião dentista

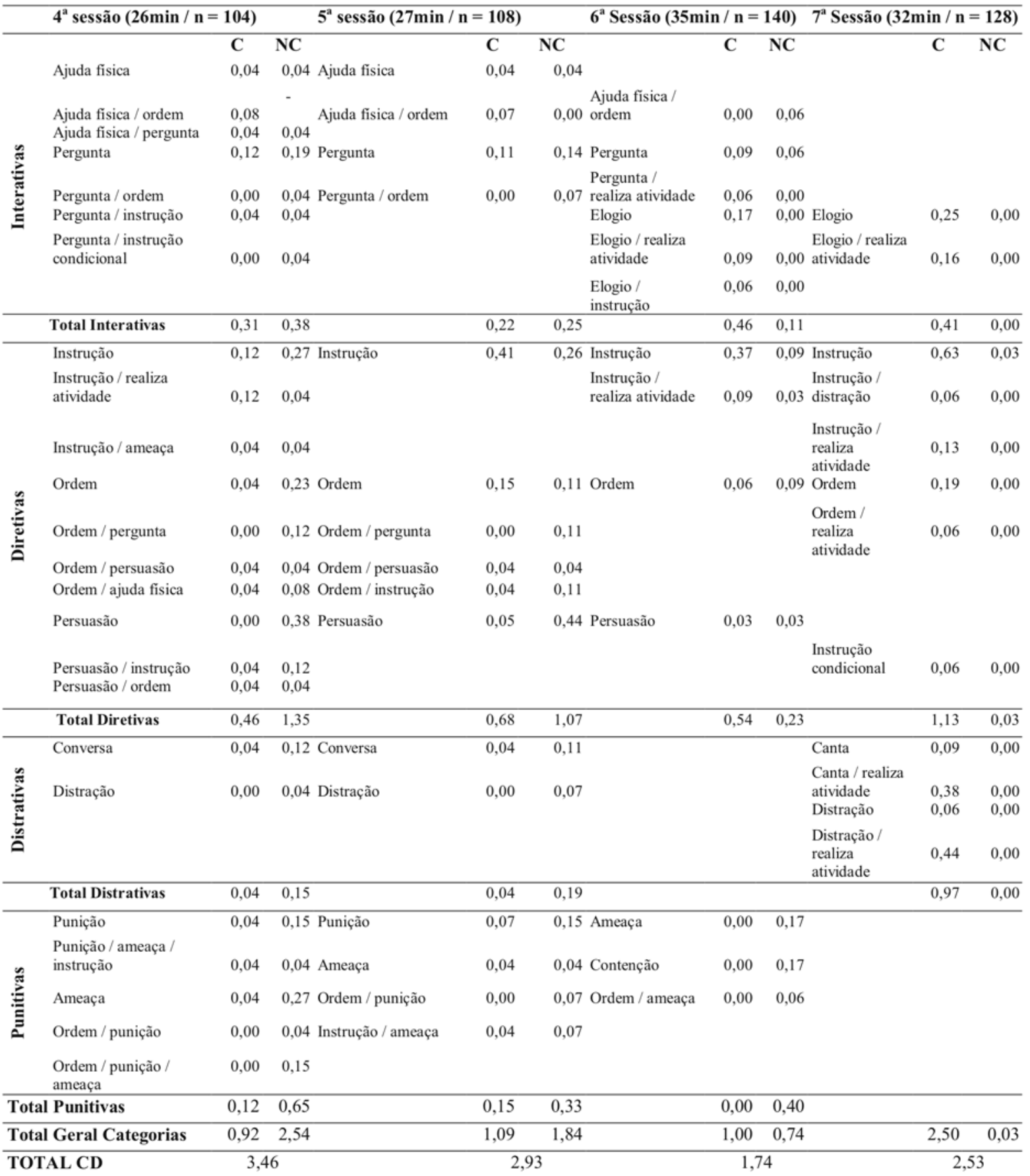


Observa-se que as categorias de comportamento do cirurgião-dentista, considerando-se os quatro grupos funcionais, apresentaram a seguinte distribuição na quarta e sétima sessões: na quarta sessão foram registradas 91 ocorrências de comportamento, sendo 18 interativas, 47 diretivas, 5 distrativas e 21 punitivas. Na sétima sessão, registraram-se 81 ocorrências, sendo 13 interativas, 37 diretivas, 31 distrativas e nenhuma punitiva. Comparando-se a quarta com a sétima sessão, verifica-se uma maior quantidade e variabilidade de categorias de comportamento do cirurgião-dentista na quarta sessão, obtendo-se tanto colaboração quanto não-colaboração da criança. Por outro lado, na sétima sessão, as categorias do cirurgião-dentista promoveram uma clara predominância de comportamentos colaborativos da criança. Devese destacar que na sétima sessão, o cirurgião-dentista não apresentou categorias punitivas de comportamento.

Analisando os dados de cada sessão, observa-se que na quarta sessão, a freqüência relativa de comportamentos colaborativos da criança $(\mathrm{C}=0,92)$ foi sempre menor que a freqüência de comportamentos não-colaborativos $(\mathrm{NC}=2,54)$. Da quarta para a sétima sessão, ocorre um aumento de colaboração da criança, sugerindo que a criança fica, gradativamente, sob maior controle de comportamentos instrucionais do cirurgião-dentista. Quando se comparam os comportamentos de instrução do cirurgiãodentista, na $6^{\underline{a}}$ sessão, com as sessões anteriores, observa-se que a instrução seguida de colaboração aumenta da $4^{\mathrm{a}}$ para a $6^{\mathrm{a}}$ sessão.

Um outro aspecto a destacar, é que os comportamentos de instrução e ordem, ambos do grupo de categorias diretivas, foram as únicas categorias que sempre ocorreram nas quatro sessões analisadas. A frequiência de comportamentos de instrução aumenta da quarta para a sétima sessão e a frequiência de comportamentos de ordem mantém-se inalterada. Observa-se, ainda, que a freqüência relativa de colaboração e nãocolaboração frente à ajuda física/ordem $(\mathrm{C}=0,08 ; \mathrm{NC}=0,00)$ e instrução/realiza atividade $(\mathrm{C}=0,12 ; \mathrm{NC}=0,04)$ apontam que a criança colaborou significativamente diante de categorias interativas e diretivas, quando disponibilizados pelo cirurgião-dentista.

Na quinta sessão, os comportamentos não-colaborativos ainda apresentavam uma freqüência relativa maior do que os registrados para os comportamentos colaborativos. No entanto, nessa sessão, os comportamentos de ajuda física/or$\operatorname{dem}(C=0,07 ; \mathrm{NC}=0,00)$, instrução $(\mathrm{C}=0,41 ; \mathrm{NC}=0,26) \mathrm{e}$ ordem $(\mathrm{C}=0,15$; $\mathrm{NC}=0,11)$ foram proporcionalmente seguidos de maior colaboração do que não-colaboração.

Comparando-se os dados da quarta e quinta sessões, observa-se um aumento na colaboração da criança quando da emissão de comportamentos de instrução do cirurgiãodentista: a colaboração passa de 0,12 , na quarta sessão, para 0,41 na sessão subseqüente, enquanto que os comportamentos de não-colaboração mantêm-se estáveis nessas sessões. A frequiência de comportamentos de ordem seguidos de colaboração aumenta de 0,04 , na quarta, para 0,15 na quinta sessão. Já os comportamentos de ordem seguidos de não-colaboração diminuem em freqüência, de 0,23 para 0,11 . Os de- mais comportamentos do cirurgião-dentista mantêm freqüências de colaboração e não-colaboração semelhantes, quando comparadas às duas sessões iniciais de atendimento.

Pode-se destacar, na sexta sessão, que os comportamentos de colaboração apresentam uma frequiência relativa maior que os de não-colaboração. Pela primeira vez, ocorrem registros de comportamentos de elogio, elogio/instrução e elogio/realiza atividade, classificados no grupo de categorias interativas. Estes comportamentos do cirurgiãodentista estão diretamente relacionados a padrões de colaboração da criança. Não foram observados comportamentos do grupo de categorias distrativas nesta sessão. Além disso, também ocorreu, pela primeira vez, registro do comportamento de contenção (do grupo de categorias punitivas), que produziu comportamentos de não-colaboração da criança em alta freqüência. Sugere-se que o aumento da colaboração, nesta sessão, esteja relacionado com a emissão de comportamentos do grupo de categorias interativas pelo cirurgião-dentista. Tal hipótese é reforçada pela observação de que, na $6^{\underline{a}}$ sessão, comparada com a $4^{\underline{a}}$ e $5^{\underline{a}}$ sessões, a freqüência de comportamentos não-colaborativos da criança diminui quando o cirurgião-dentista utiliza categorias tanto interativas quanto diretivas.

Observa-se que comportamentos de persuasão (do grupo de categorias diretivas) ocorreram com freqüências relativas de 0,38 e 0,49 para a $4^{\underline{a}}$ e $5^{\underline{a}}$ sessões, respectivamente, diminuindo, na $6^{\frac{a}{a}}$ sessão, para 0,06 . Sugere-se que a persuasão não foi eficaz para produzir colaboração da criança na $4^{\underline{a}}$ e $5^{\underline{a}}$ sessões. Assim, o cirurgião-dentista reduziu, significativamente, a emissão deste comportamento na $6^{\underline{a}}$ sessão.

Comportamentos de ajuda física/ordem ocorrem mais freqüentemente no início de cada sessão, ou seja, o dentista adota-os para preparar a criança para a rotina de atendimento. Já os comportamentos de elogio, elogio/realiza atividade ocorrem ao longo do tratamento clínico. Observa-se, ainda, que comportamentos de ajuda física/ordem ocorrem mais freqüentemente na $4^{\underline{a}}$ e $5^{\text {a }}$ sessões, do que na $6^{\mathrm{a}}$ sessão.

Observa-se, na sétima sessão, que os comportamentos de colaboração da criança $(C=2,53)$ apresentam uma freqüência significativamente maior que os comportamentos de não-colaboração $(\mathrm{NC}=0,03)$. Destaca-se, também, o aumento das frequiências relativas de categorias de comportamentos diretivas e distrativas nesta sessão. Sugere-se que os comportamentos colaborativos produzidos em função de categorias interativas e diretivas, estabeleceram a oportunidade para que o cirurgião-dentista adotasse, também, categorias distrativas de comportamento.

\section{Seqüências de interação dentista-criança}

Ainda em referência à análise funcional, os comportamentos do cirurgião-dentista também foram analisados em relação às sequiências de interação com a criança. A Tabela 3 apresenta fragmentos dos comportamentos de instrução, em cada sessão de atendimento, bem como os eventos antecedentes e conseqüentes das respostas emitidas pelo cirurgião-dentista. 
Tabela 3

Descrição de eventos ambientais e respostas do cirurgião-dentista em sessões de atendimento odontológico

\begin{tabular}{|c|c|c|c|}
\hline Antecedentes & Respostas do CD & Categoria & Conseqüentes \\
\hline & Fragmento I - 4⿳亠丷a Sessão - Exame clínico & & \\
\hline Criança sentada / olha CD & $\begin{array}{l}\text { "Você também sabe ajudar, vem! Deita } \\
\text { aqui um pouquinho" / Sinaliza para que a } \\
\text { criança deite }\end{array}$ & Ordem & Criança faz maneio de cabeça que não \\
\hline $\begin{array}{l}\text { Criança faz maneio de cabeça } \\
\text { que não }\end{array}$ & $\begin{array}{l}\text { "Você deita e a gente passa o cotonete e } \\
\text { joga um arzinho e você já vai embora, dá } \\
\text { até para você dar uma dormidinha" }\end{array}$ & Instrução & $\begin{array}{l}\text { Criança sentada / olha para CD / leva } \\
\text { mão a haste do refletor / faz maneio de } \\
\text { cabeça que não / não colabora }\end{array}$ \\
\hline \multirow[t]{2}{*}{$\begin{array}{l}\text { Criança sentada / olha para } \mathrm{CD} / \\
\text { leva mão a haste do refletor / faz } \\
\text { maneio de cabeça que não }\end{array}$} & $\begin{array}{l}\text { "Não gatinha! De novo você não vai } \\
\text { ganhar todas aquelas coisas que eu lhe } \\
\text { disse. Nem brincar com a boneca e com os } \\
\text { cartões" }\end{array}$ & Punição & $\begin{array}{l}\text { Criança sentada / olha para CD / leva } \\
\text { mão a haste do refletor / não colabora }\end{array}$ \\
\hline & 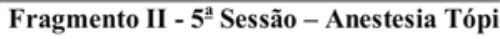 & & \\
\hline $\begin{array}{l}\text { Criança sentada / olha para CD } \\
\text { [agita-se na CO] }\end{array}$ & $\begin{array}{l}\text { "Você segura o pincel para me ajudar a } \\
\text { passar, tá! olha, pega o pincel para você } \\
\text { ver como é, oh" / Estende pincel para } \\
\text { criança }\end{array}$ & Persuasão & $\begin{array}{l}\text { Criança aperta [com as pontas dos dedos] } \\
\text { o pincel }\end{array}$ \\
\hline $\begin{array}{l}\text { Criança aperta [com as pontas } \\
\text { dos dedos] o pincel }\end{array}$ & $\begin{array}{l}\text { "Igual o pincel que a gente faz pintura tá } \\
\text { vendo só" }\end{array}$ & Instrução & $\begin{array}{l}\text { Criança segura haste do refletor com mão } \\
\text { direita / colabora }\end{array}$ \\
\hline \multirow[t]{2}{*}{$\begin{array}{l}\text { Criança segura haste do refletor } \\
\text { com mão direita / colabora / } \\
\text { permite }\end{array}$} & $\begin{array}{l}\text { "Se lembra, aqui oh. olha o dedo azul, tá } \\
\text { vendo, olha que cheiroso" /Leva mão da } \\
\text { criança ao nariz a criança }\end{array}$ & Instrução & Criança olha CD \\
\hline & 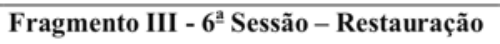 & & \\
\hline Criança colabora & $\begin{array}{l}\text { "Nossa como essa menina tá ajudando!" / } \\
\text { Intervenção com pincel }\end{array}$ & $\begin{array}{l}\text { Elogio / realiza } \\
\text { atividade }\end{array}$ & Criança colabora \\
\hline Criança colabora & $\begin{array}{l}\text { "Agora vamos passar o pincel. Tudo bom } \\
\text { ai! Agora vem a luzinha! Lembra dela?" }\end{array}$ & Instrução & Criança colabora \\
\hline \multirow[t]{2}{*}{ Criança colabora } & $\begin{array}{l}\text { Intervenção com seringa e sugador / } \\
\text { fotopoelimierizador }\end{array}$ & Realiza atividade & Criança colabora \\
\hline & \multicolumn{3}{|l|}{ Fragmento IV - $7^{\mathrm{a}}$ Sessão - Preparo cavitário } \\
\hline Criança olha abridor de boca & $\begin{array}{l}\text { "Vamos lá, Dani. abre a boca de jacaré, } \\
\text { mais ela sabe fazer uma boca gigante, hein } \\
\text { gente! Oh!" }\end{array}$ & Ordem / elogio & Criança colabora \\
\hline Criança colabora & $\begin{array}{l}\text { "Agora vamos colocar aquela sainha para } \\
\text { ver o bicho" }\end{array}$ & Instrução & Criança colabora \\
\hline Criança colabora & $\begin{array}{l}\text { "Daniela vai virar a caçadora de bicho } \\
\text { preferida e se agora a gente for bem rápido } \\
\text { vai sobrar tempo para brincar com o nenê, } \\
\text { heim!" }\end{array}$ & $\begin{array}{l}\text { Elogio / instrução } \\
\text { condicional }\end{array}$ & Criança faz maneio de cabeça que sim \\
\hline
\end{tabular}

Na Tabela 3, os comportamentos do cirurgião-dentista são descritos em termos de antecedentes, respostas e conseqüentes. São apresentados quatro fragmentos de transcrições seqüenciais, sendo que cada recorte correspondente a uma sessão diferente e a uma rotina clínica específica: $4^{\mathrm{a}}$ sessão - exame clínico; $5^{\underline{a}}$ sessão - anestesia tópica; $6^{\underline{a}}$ sessão restauração; e $7^{\underline{a}}$ sessão - preparo cavitário.

Analisando os fragmentos de cada sessão, pode-se apontar que, na rotina odontológica de exame clínico da quarta sessão, os comportamentos de instrução estão relacionados a comportamentos não-colaborativos da criança e que estes aumentam a probabilidade da emissão de respostas mais diretivas e punitivas pelo cirurgião-dentista. Parece que a criança expressava medo em relação ao ambiente odontológico, olhando fixamente para equipamentos e ins- trumentos e apresentando comportamentos de esquiva e fuga. Mesmo sob instruções e orientações acerca do que seria realizado e quais os comportamentos esperados da criança, o cirurgião-dentista não conseguiu estabelecer uma conversa com a criança. Acredita-se que os comportamentos nãocolaborativos da criança aumentaram a probabilidade da utilização de comportamentos de ordem e punição, como estratégias para prolongar a permanência da criança na cadeira odontológica.

$\mathrm{O}$ segundo fragmento se refere à rotina de anestesia tópica, na quinta sessão de atendimento. A criança permite e participa das atividades propostas pelo cirurgião-dentista, mas não colabora com a realização dos procedimentos clínicos. O fragmento comportamento de instrução pode ser relacionado aos comportamentos colaborativos da criança, que 
se manteve sentada e atenta às orientações do cirurgião dentista. Mesmo com a permissão do dentista para que a criança pudesse manusear alguns instrumentos odontológicos, ela não colaborou com o atendimento. Parece que comportamentos de instrução podem estar relacionados a comportamentos de persuasão. O dentista utilizou-se destas estratégias para manter a atenção da criança, no entanto, mostraram-se ineficazes para a obtenção de colaboração.

O terceiro fragmento foi retirado da rotina odontológica de restauração, na sexta sessão. A criança passou a emitir comportamentos colaborativos, não apenas mostrou-se atenta ou participativa nas atividades não clínicas, mas permitiu a realização do atendimento odontológico. Parece que, na sexta sessão, comportamentos de instrução podem estar relacionados à obtenção da colaboração da criança. Enquanto o cirurgiãodentista orientava sobre quais seriam os procedimentos a serem realizados, também elogiava e intervinha clinicamente. Ressalta-se que, nesta sessão, a contenção física foi utilizada no início da sessão, como uma estratégia para o manejo de comportamentos não-colaborativos. Sugere-se que o fato da criança ser contida e submetida ao tratamento odontológico possibilitou que a criança enfrentasse a situação aversiva, e assim, tivesse seu repertório de comportamentos modificado.

No último fragmento da Tabela 3 , observa-se a rotina de preparo cavitário na sétima sessão de atendimento. Observase que comportamentos de instrução podem estar relacionados a comportamentos de colaboração. Os dados sugerem que a maior frequiência de comportamentos colaborativos da criança permitiu a plena realização do tratamento clínico e também a manutenção de comportamentos de elogio e de distração pelo cirurgião-dentista. Nesta sessão, o dentista realizou o atendimento odontológico, praticamente, sem a emissão de comportamentos não-colaborativos.

\section{Discussão}

A partir da descrição das sete sessões de atendimento, da categorização e freqüência relativa dos comportamentos do dentista e da análise de fragmentos de interação social, pode-se perceber que o tratamento odontológico envolve um controle bidirecional entre seus participantes.

Segundo Ten Berge et al. (1999), o dentista utiliza-se da instrução, enquanto estratégia de manejo de comportamentos de crianças temerosas, para obter a colaboração ao tratamento odontológico. Os resultados do presente trabalho permitem corroborar as afirmações desses autores, especialmente quanto se observa que o profissional apresentou instruções praticamente durante todo o atendimento, orientando a criança sobre os procedimentos ou convidando-a para que participasse do atendimento (ver Tabela 2). A criança, por sua vez, aumentou seu grau de colaboração ao longo do atendimento.

Destaca-se que na última sessão, o cirurgião-dentista utilizou comportamentos de instrução como um procedimento do tipo conte-mostre-faça (fragmento IV da Tabela 3). É evidente que a instrução aparece como um efeito de comportamentos de colaboração da criança e, também, como sinalizador de atenção, cuidado e apoio. Mas a instrução, descrita como demonstração e orientação à criança, aparentemente deveria diminuir no decorrer das sessões. Os dados obtidos permitem a elaboração de algumas indagações: (a) o que mantém os comportamentos de instrução do cirurgião dentista, considerando que a criança já passou por todo o atendimento odontológico e foi exposta a todos os instrumentos e procedimentos clínicos disponíveis no consultório? (b) podemos inferir que a manutenção de comportamentos de instrução esteja relacionada à aprendizagem teóricatécnica do cirurgião-dentista, nem sempre condicionada ao grau de colaboração manifestado pelo paciente?

Ainda em relação ao manejo de comportamentos da criança por meio de estratégias não punitivas, pode-se perceber que nas quatro últimas sessões, o dentista somente utilizou comportamentos distrativos na $6^{\underline{\underline{a}}}$ e $7^{\underline{a}}$ sessões, os quais estão relacionados à colaboração da criança (conforme Tabela 2). O cirurgião-dentista utiliza distração somente quando a criança mostra-se colaboradora, o que está de acordo com os estudos de Stark et al. (1989) e Singh et al. (2002), nos quais a estratégia distração é apontada como potencialmente eficaz à manutenção de comportamentos colaborativos.

Pôde-se perceber também, que o profissional, frente a padrões de não-colaboração da criança, utiliza comportamentos de persuasão, oferecendo prêmios ou recompensas para a obtenção de controle da criança. Estes comportamentos não se mostraram eficazes para o manejo de comportamentos não-colaborativos. Tal resultado também está de acordo com Singh et al. (2002) e Stark et al. (1989), que discutem a tendência ao aumento da esquiva e fuga quando os profissionais condicionam presentes ou recompensas à redução ou eliminação de comportamentos não-colaborativos.

Com relação aos comportamentos de não-colaboração, as descrições das sessões demonstram que a criança, nas cinco primeiras sessões de atendimento, permitiu a execução total ou parcial de procedimentos clínicos considerados nãoinvasivos, incluindo evidenciação de placa, aplicação tópica de flúor e anestesia tópica. No entanto, quando o cirurgiãodentista iniciou um procedimento invasivo (anestesia injetável), a criança não permitiu a continuação do atendimento ( $3^{\underline{a}}$ sessão). A criança, quando exposta à sensações de dor e/ou desconforto passa a impedir ou dificultar o atendimento, tal como descrevem de Jongh et al. (1995).

Parece que a criança discrimina facilmente os eventos clínicos. Na segunda sessão, o dentista somente conseguiu realizar a anestesia tópica e na terceira sessão, a criança permitiu a anestesia tópica, mas, diante da sensação desagradável da injeção anestésica, apresentou comportamentos nãocolaborativos que impediram a continuação da sessão.

Ainda sobre o manejo de comportamentos nãocolaborativos, o cirurgião-dentista utilizou-se de comportamentos punitivos, tais como punição verbal, ameaça e contenção física. Weinstein et al. (1982) apontam a utilização de punição verbal para controle de comportamentos nãocolaborativos como uma estratégia eficaz. Singh et al. (2002) descrevem a punição como a única estratégia eficaz para o controle de crianças muito temerosas. Os resultados deste estudo também apontam que o cirurgião-dentista, frente a 
comportamentos não-colaborativos, tende a adotar estratégias de contenção física e que tais estratégias, funcionalmente punitivas, conduzem à diminuição da frequiência de comportamentos não-colaborativos da criança.

Com relação à eficácia da contenção física para o manejo de comportamentos não-colaborativos, observa-se, na Tabela 2, que a freqüência relativa de colaboração tendia a aumentar, ou se estabilizar, da quarta à sexta sessão (na $4^{\underline{a}}$ sessão a colaboração geral foi de 0,92 , passando para 1,09 e depois para 1,00), enquanto que a freqüência de não-colaboração, ao contrário, diminuía da $4^{\text {a }}$ para a $6^{\underline{a}}$ sessão $(2,54 ; 1,84$ e 0,74$)$. Pode-se inferir que a criança estava adaptando-se ao atendimento odontológico, reduzindo seu padrão de não-colaboração e passando a permitir que as intervenções clínicas fossem executadas mais facilmente. Assim, questiona-se se a estratégia de contenção física era realmente imprescindível neste atendimento, uma vez que a criança vinha colaborando gradativamente mais com o decorrer das sessões e a contenção física somente foi utilizada na $6^{\underline{a}}$ sessão $(0,17)$. Sugere-se que esta criança não necessitaria de contenção física, mas de um maior número de sessões de atendimento para a conclusão do tratamento. Os dados obtidos permitem apontar que a análise funcional é um instrumento valioso para identificar as relações que se estabelecem entre diferentes classes de comportamentos e variáveis contextuais, clínicas e arbitrárias da situação odontológica.

\section{Referências}

Addelston, H. K. (1959). Child patient training. Fortinightly Review of the Chicago Dental Society, 38(2), 27-30.

Allen, K. D., Loiben, T., Allen, A. J., \& Stanley, R. T. (1992). Dentistimplemented contingent escape for management of disruptive child behavior. Journal of Applied Behavior Analysis, 25, 629-636.

Cerqueira, A. T. (2000). O conceito e metodologia de coping: existe consenso e necessidade? In R. A. Banaco (Org.), Sobre comportamento e cognição: aspectos teóricos e de formação em análise do comportamento e terapia cognitiva (pp. 279-289). Santo André: ArBytes.

Coutinho, S. M. G., Costa Jr., A. L., \& Kanitz, S. (2000). Manejo de variáveis psicológicas no tratamento do câncer em crianças: algumas contribuições da psiconeuroimunologia. Estudos de Psicologia, 17, 33-42.

de Jongh, A., Muris, P., Horst, G., \& Duyx, P. M. A. (1995). Acquisition and maintenance of dental anxiety: the role of conditioning experiences and cognitive factors. Behavior Research and Therapy, 33, 2, 205-210.

Liddel, A., \& Locker, D. (2000). Changes in levels of dental anxiety as a function of dental experience. Behavior Modification, 24, 57-68.

Matos, M. A. (1997). O behaviorismo metodológico e suas relações com o mentalismo e o behaviorismo radical. In R. A. Banaco (Org.), Sobre comportamento e cognição: aspectos teóricos e de formação em análise do comportamento e terapia cognitiva (pp. 54-67). Santo André: ArBytes.

Moraes, A. B. A. (1997). Saúde bucal e comportamento. In D. R. Zamignani (Org.), Sobre comportamento e cognição: a aplicação da análise do comportamento e da terapia cognitivo-comportamental no hospital geral e nos transtornos psiquiátricos (pp. 57-66). Santo André: ArBytes.

Moraes, A. B. A., \& Pessotti, I. (1985). Psicologia aplicada à Odontologia. São Paulo: Sarvier.

Possobon, R. F. (2000). Uso combinado de estratégias comportamentais e farmacológicas no manejo da criança não-colaboradora durante o atendimento odontológico. Dissertação de mestrado não publicada, Faculdade de Odontologia de Piracicaba, Universidade Estadual de Campinas, Piracicaba.

Singh, K. A. S., Moraes, A. B. A., \& César, J. (2002). Análise funcional do comportamento do dentista no contexto de sua atuação profissional. Acta Comportamentalia, 10, 181-198.

Skinner, B. F. (1945). The operational analysis of psychological terms. Psychological Review, 52, 270-277.

Skinner, B. F. (1953). Science and human behavior. Nova York: Macmillan.

Stark, L. J., Allen, K. D., Hurst, M., Nash, D. A., Rigney, B., \& Stokes, T. F. (1989). Distraction: its utilization and efficacy with children undergoing dental treatment. Journal Applied of Behavior Analysis, 22, 297-307.

Ten Berge, M., Veerkamp, J., \& Hoogstraten, J. (1999). Dentist's behavior in response to child dental fear.Journal of Dentistry for Children, 66, 36-40.

Vanderberghe, L. (2002). A prática e as implicações da análise funcional. Revista Brasileira de Terapia Comportamental e Cognitiva, 4, 35-46.

Weinstein, P., Getz, T., Rateener, P., \& Domoto, P. (1982). Dentist's responses to fear and nonfear related behaviors in children. Journal_of the American Dentistry Association, 104, 38-40.

Nota

1 Trabalho realizado com o apoio financeiro da Fapesp

Gustavo S. Rolim, psicólogo, atua no Centro de Pesquisa e Atendimento Odontológico para Pacientes Especiais, Faculdade de Odontologia de Piracicaba, UNICAMP. Email: gurolim@ caramail.com

Antônio Bento Alves de Moraes, doutor em Psicologia, é professor no Centro de Pesquisa e Atendimento Odontológico para Pacientes Especiais, Faculdade de Odontologia de Piracicaba, UNICAMP. Endereço para correspondência: Faculdade de Odontologia de Piracicaba/FOP, Universidade Estadual de Campinas; Av. Limeira, 901; Piracicaba, SP; CEP 13414-018. E-mail: abento@ fop.unicamp.br

José César, mestre em psicologia, é professor na Faculdade de Psicologia da Universidade Metodista de Piracicaba.

Áderson Luiz Costa Junior, doutor em psicologia, é professor adjunto no Instituto de Psicologia da Universidade de Brasília.E-mail: aderson@unb.br 